Printed in Great Britain

\title{
Stalk Elongation in Mutants of Caulobacter crescentus
}

\author{
By JEAN M. SCHMIDT \\ Department of Botany, Arizona State University, Tempe, Arizona, 8528 I U.S.A.
}

(Accepted for publication I I April I968)

\begin{abstract}
SUMMARY
Morphological mutants of Caulobacter crescentus, which undergo extensive stalk elongation when grown on complex medium, were isolated by an indirect selection technique. Wild-type $C$. crescentus is known to produce a similar morphological defect when grown under conditions of severe phosphate limitation. The maximum stalk length of the mutants was $20 \mu$, as compared with 2 to $3 \mu$ for the parent strains. In these mutant strains, stalk synthesis proceeded in individual bacteria as long as they remained viable. This was in contrast to the wild-type bacteria cultivated on complete medium, where stalk growth reached completion within the first few generations. The mutants had no organic growth factor requirements, but their growth rates were considerably slower than those of the wild-type strains. Two of the mutants showed conditional phenotypic reversion to normal stalk formation when cultivated in the presence of relatively high inorganic phosphate concentrations $\left(\mathrm{IO}^{-2} \mathrm{M}\right)$. No ultrastructural defects in the mutants were noted, other than the excessive stalk length. Genotypic reversion rates for backmutation to short stalk formation were estimated.
\end{abstract}

\section{INTRODUCTION}

The morphogenesis and ultrastructure of vibrioid Caulobacter species have received considerable attention (review by Poindexter, 1964; Poindexter \& CohenBazire, 1964; Cohen-Bazire, Kunisawa \& Poindexter, 1965; Schmidt \& Stanier, 1966). A growing culture of Caulobacter crescentus contains motile vibrioid swarmer bacteria possessing a polar flagellum, and non-motile stalked bacteria. The stalked bacterium divides by transverse binary fission, and the swarmer, before division, develops its stalk at a location corresponding to the site of attachment of the flagellum (Stove \& Stanier, 1962; Poindexter, 1964). Ultrastructural investigations demonstrated that the stalk is enclosed by a multi-layered wall which is continuous with the bacterial cell wall, and that the cytoplasmic membrane continues into the stalk to enclose its core (Poindexter, I964; Poindexter \& Cohen-Bazire, I964). This core is composed of a membranous material which extends from a differentiated membranous region at the pole of the bacterial cell. The polar membranous region associated with the stalk is structurally distinct from the mesosomes which originate from the cytoplasmic membrane and which also may occur in this region of the bacterium (CohenBazire et al. 1965). Stalk growth occurs at the juncture of the stalk with the bacterial cell, and the stalk wall is a relatively inert, non-growing structure (Schmidt \& Stainer, I966).

These studies have raised interest in the biochemical activities which accompany and control stalk development. In one approach to this problem, mutant strains with

Vol. 53, No. 2, was issued 30 September 1968 
aberrations in their stalk development have been sought for biochemical characterization. This paper reports the isolation of mutants of Caulobacter crescentus which undergo extensive stalk elongation when cultivated on standard complex growth medium. These mutants will be referred to by the phenotypic abbreviation, Skl, which stands for stalk length. The morphology, ultrastructure and growth characteristics of several Skl mutant isolates are described here.

\section{METHODS}

Bacteria and cultural conditions. Caulobacter crescentus strains CBI5 (ATCC 19089) and CBI were obtained from Dr Jeanne Poindexter. The standard complex growth medium (PYE) and the glucose + imidazole defined medium $(\mathrm{G}+\mathrm{I})$ were as previously described (Poindexter, 1964; Schmidt \& Stanier, 1966). Cultures were incubated at $30^{\circ}$; liquid cultures were grown in flasks in a rotary shaker water bath (New Brunswick Scientific, Model G 76) at $130 \mathrm{rev} / \mathrm{min}$. to provide adequate aeration.

Isolation of mutants. Mutagen treatment of Caulobacter crescentus wild-type cultures with ultraviolet radiation or ethylmethane-sulphonate (EMS) was used. For u.v.radiation, an exponential culture in PYE broth was diluted I/IO in G+I medium to give about $5 \times 10^{7}$ bacteria $/ \mathrm{ml}$. The bacteria were irradiated 3 to $4 \mathrm{~min}$. at a distance of I4 cm. with a Mineralite USV-I I lamp. This treatment gave I to $0.1 \%$ survival. The irradiated cultures were diluted in PYE broth and PYE spread plates prepared.

A method adapted from Strauss (1962) and Paleroni \& Stanier (1964) was used in EMS treatments. Two ml. of bacterial culture in the late exponential stage of growth were harvested and resuspended in I $\mathrm{ml}$. of $0.03 \mathrm{M}$-phosphate buffer $(\mathrm{pH} \mathrm{7})$. The buffered suspension was added to I $\mathrm{ml}$. of $2 \%(\mathrm{v} / \mathrm{v})$ EMS (Eastman Organic Chemicals) in 0.1 M-phosphate buffer ( $\mathrm{pH} 7$ ). The mixture was incubated at $30^{\circ}$ for 70 to $90 \mathrm{~min}$. to obtain I to $0.1 \%$ survival. The EMS-treated bacteria were diluted into $5 \%(\mathrm{w} / \mathrm{v})$ $\mathrm{Na}_{2} \mathrm{~S}_{2} \mathrm{O}_{3}$ to destroy residual mutagen. Subsequent dilutions were made in PYE broth, and $O_{1} \mathrm{I} \mathrm{ml}$. samples were plated on PYE agar. After growth appeared, the colonies were used in preparing PYE agar patch plates to obtain sufficient growth, originating from individual colonies, for further observation. After growth of patch areas had occurred, bacteria from the patches were examined with a phase-contrast microscope at a magnification $\times 1250$. When morphological mutants were detected, bacteria from corresponding patch areas were streaked on PYE agar.

Growth rate, viability, and biochemical determinations. Growth rates were estimated turbidimetrically with a Klett-Summerson photoelectric colorimeter with a no. 66 filter. Five ml. of inocula from PYE or $\mathrm{G}+\mathrm{I}$ liquid cultures in the exponential phase of growth were added to respective flasks containing $30 \mathrm{ml}$. of PYE or G+I broth; growth experiments continued for 12 to $15 \mathrm{hr}$.

To determine \% viable forms in late exponential phase PYE cultures, viable counts (colony forming units $/ \mathrm{ml}$.) were obtained from PYE spread plates inoculated with appropriate dilutions of the culture; direct counts of bacteria were done by using a Petroff-Hausser counting chamber. Rosettes were counted as one colony-forming unit.

The poly- $\beta$-hydroxybutyrate content was estimated gravimetrically (Williamson \& Wilkinson, 1958) on Caulobacter cultures grown in $\mathrm{G}+\mathrm{I}$ medium containing $\mathrm{IO}^{-3} \mathrm{M}-$ inorganic phosphate.

Preparations for electron microscopy. The method of Brenner \& Horne (1959) as 
modified by Bradley (1962) was used for negative stains. A suspension of bacteria $\left(10^{8} / \mathrm{ml}\right.$.) was prepared in distilled water. A drop of the suspension was placed on a clean glass slide and mixed with a drop of $2 \%(\mathrm{w} / \mathrm{v})$ sodium phosphotungstate containing $0.4 \%$ sucrose. A formvar-coated carbon-stabilized grid was dipped in the suspension of stained bacteria and allowed to dry before electron microscopic observation.

For preparation of thin sections, a modification of the method of Ryter \& Kellenberger (I958) was used. The veronal + acetate buffer used in fixation was at $\mathrm{pH} 6 \cdot 8$. Bacteria were fixed in I \% osmium tetroxide for $2.5 \mathrm{hr}$. The embedding medium was Vestopal (Polysciences, Inc.), polymerized at $60^{\circ}$ for $48 \mathrm{hr}$. Sections were obtained with a MT-I ultramicrotome (Sorvall), post-stained with lead citrate (Reynolds, 1963), and observed with a Philips Ioo B electron microscope operated at $60 \mathrm{kV}$.

Genotypic reversion rate estimation. The Poisson distribution method (Luria \& Delbrïck, 1943; Witkin, 1950) was used for approximation of the genetic reversion rate of several Caulobacter crescentus Skl mutants to revertant forms with stalks of normal length. The revertants were detected since they grew faster and formed larger colonies than the Skl strains; their presence was verified by microscopic examination. The fraction of apparent non-revertant colonies among total colonies $\left(P_{0}\right)$ on six PYE spread plates was determined for each of five Skl strains. Each colony was considered to represent an independent culture. The average number of bacteria per colony (N) was determined by making direct microscopic counts of bacteria from Skl colonies suspended in $0.1 \mathrm{ml}$. PYE broth. This adaptation of the Poisson mutation rate estimation makes the assumptions that no revertants were present among the Skl bacteria originally plated, and that revertants which occurred during the growth of the colonies would give rise to larger and distinctive revertant colony forms.

Extracts of Caulobacter crescentus. Late exponential phase cultures of wild-type C. crescentus $\mathrm{CBI}$ and $\mathrm{CBI} 5$ were treated ultrasonically for I min. with a cooled probe (Model S 75, Branson Instruments, Inc.). The suspensions were then centrifuged at $3000 \mathrm{~g}$ for Io min. The supernatant fluids were passed through a Millipore type HA filter and the filtrates used in phenotypic reversion experiments.

Phenotypic reversion determinations. $\mathrm{G}+\mathrm{I}$ or PYE agar media containing added inorganic salts $\left(\mathrm{Na}_{2} \mathrm{HPO}_{4}\right.$ and $\mathrm{KH}_{2} \mathrm{PO}_{4}, 2 \times 10^{-4}$ to $2 \times 10^{-2} \mathrm{M} ; \mathrm{KCl}, \mathrm{NaCl}, \mathrm{CaCl}_{2}, \mathrm{MgCl}_{2}$ or $\mathrm{MgSO}_{4} \cdot 7 \mathrm{H}_{2} \mathrm{O}$, all at $2 \times 10^{-2} \mathrm{M}$ ), filtrates of wild-type bacterial extracts (10 $\%, \mathrm{v} / \mathrm{v}$ ), pantoyl lactone (Nutritional Biochem. Corp., $\mathrm{IO}^{-4} \times 3$ to $1 \mathrm{O}^{-1} \mathrm{M}$ ), and calcium Dpantothenate (Calbiochem, $0 \cdot \mathrm{I}$ to Io $\mu \mathrm{g}$. $/ \mathrm{ml}$.) were prepared. Skl strains were streaked on the phenotypic reversion (PR) media, and after growth, the bacteria examined microscopically. When a majority of the bacteria possessed stalks much shorter than the usual Skl morphology, bacteria from the PR plate were re-streaked on PYE agar and after growth had occurred, their morphology examined. A return to SkI morphology on the PYE plate indicated that conditional reversion, rather than back mutation, had occurred on the PR medium. A second method of testing filtrates of bacterial extracts was used: $0.1 \mathrm{ml}$. of extract was added to 'penicylinders' (Fisher Scientific Co.) which were placed over the regions of Skl inocula on PYE agar plates. 


\section{RESULTS}

\section{Isolation of Skl mutants of Caulobacter crescentus}

Several Skl mutants of Caulobacter crescentus which undergo extensive stalk elongation on PYE medium have been isolated by an indirect selection technique. The morphological aberration in these mutant strains is readily detectable by using highresolution phase-contrast microscopy, and is comparable to the morphological effect of inorganic phosphate starvation on wild-type C. crescentus strains (Schmidt \& Stanier, 1966). The Sk1 mutant strains, grown on PYE medium without deliberate phosphate starvation, developed stalks with maximum lengths I 2 to $20 \mu$. Not all of the stalks were of maximum length in Skl cultures that had not yet reached the stationary phase of growth, since swarmer bacteria continually appeared with each new generation and produced stalks that were shorter than those of bacteria which had originated earlier in the culture. This variability in stalk lengths was also observed in growing cultures of phosphate-limited wild-type C. crescentus (Schmidt \& Stanier, 1966).

$\begin{array}{ccc}\text { Table I. Source of Skl mutants of Caulobacter crescer } & \begin{array}{c}\text { Mutant strain } \\ \text { designation }\end{array} \\ \text { Parent strain } & \text { Mutagen } & \text { Skl 418 } \\ \text { CBI5 } & \text { EMS } & \text { Sk1 1413 } \\ \text { CBI5 } & \text { EMS } & \text { Sk1 UV23 } \\ \text { CBI5 } & \text { U.v. } & \text { Skl 219 } \\ \text { CBI } & \text { EMS } & \text { Skl 220 } \\ \text { CBI } & \text { EMS } & \text { Skl 221 } \\ \text { CBI } & \text { EMS } & \end{array}$

Six Skl isolates were chosen for further study (Table I). In the absence of a direct selection technique for Sk1 mutants, most of the mutagen experiments gave few, if any, $\mathrm{Skl}$ isolates. The detection of Skl strains was aided somewhat by the slower growth of the mutants, giving rise to Skl colonies that were smaller than those of wild-type bacteria. All unusually small or minute colonies were given particular attention on the primary isolation plates. However, this was not a specific differential character since many mutations besides those which affected stalk length also affected colony size. The colour of Skl colonies differed from that of wild-type strains. Skl colonies are chalk white; wild-type colonies are cream-coloured. However, in examining the very small colonies on the primary isolation plates, this was not a particularly obvious differentiation aid.

\section{Morphology}

Negatively stained preparations of wild-type Caulobacter crescentus strains CBI and CBI5 are shown in Pl. I, fig. I, 2. Similar preparations of Skl mutants 4I 8 and UV23 (derived from CBI5) and Skl mutant 220 (from CBI) are shown in Pl. I, fig. 3, Pl. 2, fig. 4 , 5. The excessively long stalks of the Skl strains contained relatively few crossbands. Three or four crossbands appeared in Skl bacterial stalks; wild-type bacteria from the stationary phase of growth often possessed as many. The Skl mutants frequently had a somewhat aberrant cellular morphology. The bacteria appeared slightly elongated and serpentine, and occasionally seemed to encounter difficulty in completing the binary fission process. However, filamentous bacteria were seldom encountered in Skl cultures, and daughter swarmer bacteria were notably present in 
growing Skl cultures. Poly- $\beta$-hydroxybutyric acid deposits, which appeared as electronlight intracellular granules, were frequently seen in Skl bacteria, but occurred less extensively than in the phosphate-limited wild-type C. crescentus (P1. 3, fig. 6).

\section{Poly- $\beta$-hydroxybutyric acid accumulation}

Extensive poly- $\beta$-hydroxybutyric acid deposition is characteristic of unbalanced growth in Caulobacter, particularly under conditions of nitrogen starvation (Poindexter, 1964) or phosphate limitation (Schmidt \& Stanier, 1966). Some of the Skl strains appeared to accumulate substantial quantities of poly- $\beta$-hydroxybutyric acid when observed in light and electron microscopic preparations. Gravimetric determinations for this reserve compound were made on the Skl and wild-type strains. The only Skl isolate with a markedly increased poly- $\beta$-hydroxybutyric acid content was UV 23 ( $150 \mu \mathrm{g} . / \mathrm{mg}$. dry wt, compared to $100 \mu \mathrm{g}$./mg. for the parent strain CBI5). The other Skl strains had amounts which compared closely to that of their parent strain.

\section{Ultrastructure}

Electron micrographs of thin-sectioned Skl mutants were compared with those of similarly prepared wild-type organisms. No particularly unusual ultrastructural features of the Skl strains were noted (Pl. 3, fig 7; Pl. 4, fig. 8). Thin sections of Skl bacteria along the entire long axis, including the excessively long stalks, were seldom obtained. Thin sections of very long stalks were occasionally observed, and except for their excessive length, ultrastructural organization was similar to that of the wild-type Caulobacter. The polar differentiated membranous region, from which stalk growth is thought to begin, was comparable in Skl and wild-type strains.

\section{Growth and viability characteristics}

The growth rates of the Skl mutants in PYE medium were considerably slower than those of the parental strains and the \% viable bacteria in late exponential phase PYE cultures were lower for Skl bacteria than for wild-type cultures (Table 2). The loss of viability in older Sk1 cultures compared with that in phosphate-limited wild-type cultures.

\section{Table 2. Growth characteristics of Caulobacter crescentus strains}

\begin{tabular}{|c|c|c|c|}
\hline Strain & Growth medium & $\begin{array}{c}\text { Doubling } \\
\text { time } \\
\text { (hr) }\end{array}$ & Viability $(\%)$ \\
\hline CBI5 wild-type & $\begin{array}{l}\text { Peptone + yeast-extract } \\
\text { (PYE) }\end{array}$ & $\mathrm{I} \cdot 8$ & $\begin{array}{l}\text { Not done, due to } \\
\text { rosette formation }\end{array}$ \\
\hline CB15 wild-type & $\begin{array}{l}\text { Glucose }+ \text { imidazole }+ \\
\text { IO }^{-3} \text { M-phosphate }\end{array}$ & 3 & 100 \\
\hline CBI5 wild-type & $\begin{array}{l}\text { Glucose }+ \text { imidazole no } \\
\text { added phosphate }\end{array}$ & 5 & 46 \\
\hline CBI5 Sk1 4I 8 & & IO & 70 \\
\hline CBI5 Skl I4I3 & & 5 & 49 \\
\hline CBI 5 Skl UV23 & & 5 & 80 \\
\hline CBI wild-type & PYE & 2 & $\begin{array}{l}\text { Not done, due to } \\
\text { rosette formation }\end{array}$ \\
\hline CBI Skl 219 & & 8 & 48 \\
\hline CBI Skl 220 & & 8 & 49 \\
\hline CBI Skl 22I & & 6 & $4 \mathrm{I}$ \\
\hline
\end{tabular}




\section{Genotypic reversion}

Skl strains frequently underwent back mutations to morphological forms having stalks of normal length and growing faster than the Skl mutants. The revertants often were not identical phenotypically with the original wild type, and frequently showed aberrations in cell division. Bacterial filament formation was commonly observed among the revertants. The occurrence of back mutation necessitated occasional re-isolation of Skl strains maintained in vegetative culture. Twenty \% or less of the isolated colonies of Skl strains gave detectable revertants, as determined from larger colony size and subsequent microscopic examination. Results of reversion rate estimations for five Skl strains are given in Table 3. The reversion rate of strain UV23 was not determined because its revertant colonies did not differ significantly in size from Sk1 colonies. The other five strains gave revertant colonies that were easily detectable (Pl. 4, fig. 9). In the method applied here, mutations resulting in reversion that occurred late in the growth of Skl colonies might not result in detectable colony differences, and the reversion rate obtained probably appears to be lower than might actually be the case. Because of the lack of a direct selective technique, the mutation rate of normal wild type Caulobacter crescentus to Skl mutants was not determined.

\section{Table 3. Genotypic reversion rates and frequencies of Skl mutants of Caulobacter crescentus}

\begin{tabular}{lcc}
\multicolumn{1}{c}{ Strain } & $\begin{array}{c}\text { Estimated reversion } \\
\text { rate* (no. mutations/ } \\
\text { cell/generation) }\end{array}$ & $\begin{array}{c}\text { Frequency of } \\
\text { occurrence of } \\
\text { revertant } \\
\text { colonies }\end{array}$ \\
CBI5 Skl 418 & $1 \cdot 1 \times 10^{-8}$ & 0.20 \\
CBI5 Skl 1413 & $1.5 \times 10^{-8}$ & 0.23 \\
CBI Skl 219 & $6.9 \times 10^{-9}$ & 0.15 \\
CBI Skl 220 & $7.5 \times 10^{-9}$ & 0.12 \\
CBI Skl 22I & $6.3 \times 10^{-9}$ & 0.12
\end{tabular}

* $a=-(\ln 2)\left(P_{0}\right) / N$, where $a=$ the mutation rate, $P_{0}=$ the proportion of non-revertant colonies and $N=$ the average number of bacteria/Skl colony.

\section{Conditional phenotypic reversion}

Of the several inorganic and organic compounds tested, only inorganic phosphate at concentrations greater than $\mathrm{IO}^{-2} \mathrm{M}$ gave reproducible phenotypic reversion with any of the Skl mutants. Skl strains UV23 and I4I3 responded conditionally to high phosphate concentrations, producing stalks that were only 5 to Io $\mu$ in length, then returned to typical Skl morphology when subcultured on PYE medium. The Skl mutants derived from strain CBI also showed a slight degree of conditional reversion on media with $\mathrm{IO}^{-2} \mathrm{M}$-phosphate. However, stalk lengths of the Skl mutants of $\mathrm{CBI}$ in high phosphate medium were usually greater than 1o $\mu$ so the repression of stalk elongation by phosphate was not as effective in these CBI mutants. Skl strain 418 , derived from CBI5, did not respond to phosphate or to any of the other compounds tested. Filtrates of wild-type bacterial extracts allowed no phenotypic reversion of the Skl strains. 


\section{DISCUSSION}

The possibility that some of the Skl mutants obtained may possess defects in phosphate uptake or metabolism is suggested by the conditional phenotypic reversion of these mutants to forms with almost normal stalk length when grown in the presence of high phosphate concentrations. However, some of the Skl isolates responded only slightly or not at all to the phosphate concentrations tested, implying that control of stalk formation may be affected by factors other than the availability of inorganic phosphate.

The mutations resulting in Skl morphology are somewhat detrimental to the growth and survival of the bacteria. Despite their decreased viability and slower growth rates, the Skl mutants of Caulobacter crescentus appear to offer an opportunity for further study of the control of bacterial stalk formation.

This investigation was supported by Public Health Service grant GM-I5287 from the National Institute of General Medical Sciences (U.S.), and by a Faculty Grant-inAid from Arizona State University.

I wish to thank Mr J. Swafford for the use of facilities of the Electron Microscope Laboratory.

\section{REFERENCES}

BradLey, D. E. (1962). A study of the negative staining process. J. gen. Microbiol. 29, 503.

Brenner, S. \& Horne, R. W. (I959). A negative staining method for high resolution electron microscopy of viruses. Biochim. biophys. Acta 34, 103.

Cohen-Bazire, G., Kunisawa, R. \& Poindexter, J. S. (1965). The internal membranes of Caulobacter crescentus. J. gen. Microbiol. 42, $30 \mathrm{I}$.

LuRIA, S. E. \& DelbruCK, M. (1943). Mutations of bacteria from virus sensitivity to virus resistance. Genetics 28, 49I.

Paleroni, N. J. \& Stanier, R. Y. (I964). Regulatory mechanisms governing synthesis of the enzymes for tryptophan oxidation by Pseudomonas fluorescens. J. gen. Microbiol. 35, 319.

PoIndexter, J. S. (1964). Biological properties and classification of the Caulobacter group. Bact. Rev. 28, 23 I.

PoindeXter, J. S. \& Cohen-Bazire, B. (1964). The fine structure of stalked bacteria belonging to the family Caulobacteraceae. J. Cell Biol. 23, 587.

REYNOLDS, E.S. (1963). The use of the lead citrate at high $\mathrm{pH}$ as an electron-opaque stain in electron microscopy. J. Cell Biol. r7, 208.

Ryter, A. \& Kellenberger, E. (I958). Étude au microscope électronique de plasmas contenant de l'acid désoxyribonucléique. I. Les nucléoides des bactéries en croissance active. $Z$. Naturforsch. $\mathbf{1 3} b, 597$.

Schmidt, J. M. \& Stanier, R. Y. (1966). The development of cellular stalks in bacteria. J. Cell Biol. 28, 423 .

Stove, J. L. \& Stanier, R. Y. (1962). Cellular differentiation in stalked bacteria. Nature, Lond. r96, II 89.

Strauss, B. S. (1962). Response of Escherichia coli auxotrophs to heat after treatment with mutaggenic alkyl methanesulfonates. J. Bact. 83, $24 \mathrm{I}$.

Williamson, D. H. \& Wilkinson, J. F. (1958). The isolation and estimation of poly-beta-hydroxybutyrate inclusions of Bacillus species. J. gen. Microbiol. 19, 198.

WrTKIN, E. M. (1950). Bacterial mutations involving resistance to destructive agents. Meth. med. Res. 3, 312 . 


\section{EXPLANATION OF PLATES}

Abbreviations used in figures: $\mathrm{S}$, stalk; $c$, core of stalk; $c b$, cross-band in wall of stalk; $f$, flagellum; $p$, poly- $\beta$-hydroxy-butyric acid granule; $\mathrm{R}$, revertant colony.

\section{Plate I}

Caulobacter crescentus strains, cultivated in PYE medium, and negatively stained with phosphotungstate.

Fig. I. CBI 5 wild-type. Magnification $\times 10,500$.

Fig. 2. CBI wild-type. Magnification $\times 10,500$.

Fig. 3. CBI 5 Sk1 mutant 418 . The core of the stalk can be discerned. Magnification $\times 17,500$.

\section{Plate 2}

Skl mutants of $C$. crescentus, cultivated in PYE medium, and negative-stained with phosphotungstate.

Fig. 4. CBI 5 Skl mutant UV 23. Magnification, $\times 9000$.

Fig. 5. CBI Skl mutant 220. Magnification, $\times$ I4,500.

\section{Plate 3}

Fig. 6. C. crescentus $\mathrm{CBI} 5$ wild-type, grown under conditions of phosphate starvation in G-I medium, with $10^{-5} \mathrm{M}$-phosphate. The bacteria contain massive accumulations of poly- $\beta$-hydroxybutyric acid. Magnification $\times 10,000$.

Fig. 7. Thin section of mutant Skl 418, fixed with osmic acid, embedded in Vestopal, and post-stained with lead citrate. Magnification, $\times 46,200$.

\section{Plate 4}

Fig. 8. Thin section of mutant Skl uv 23. Magnification $\times 42,000$.

Fig. 9. A PYE agar spread culture of Skl mutant 418 after incubation for $72 \mathrm{hr}$. Examination of the bacterial morphology of the colonies with a phase-contrast microscope revealed that the seven large prominent colonies contained predominantly revertant bacteria with stalks of normal length. The small colonies consisted of caulobacters with Skl-mutant morphology. 
Journal of General Microbiology, Vol. 53, No. 3

Plate I

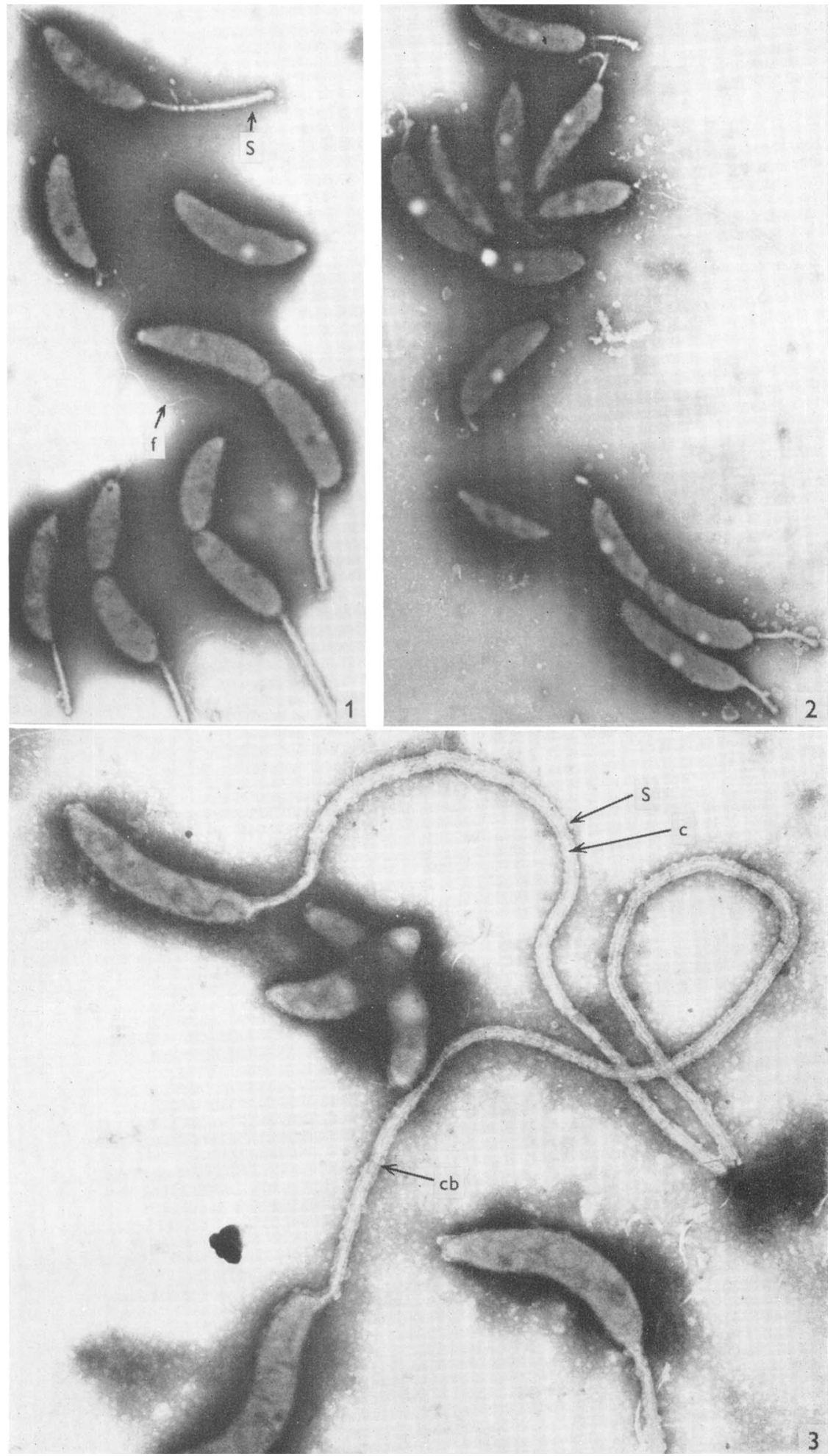


Journal of General Microbiology, Vol. 53, No. 3

Plate 2
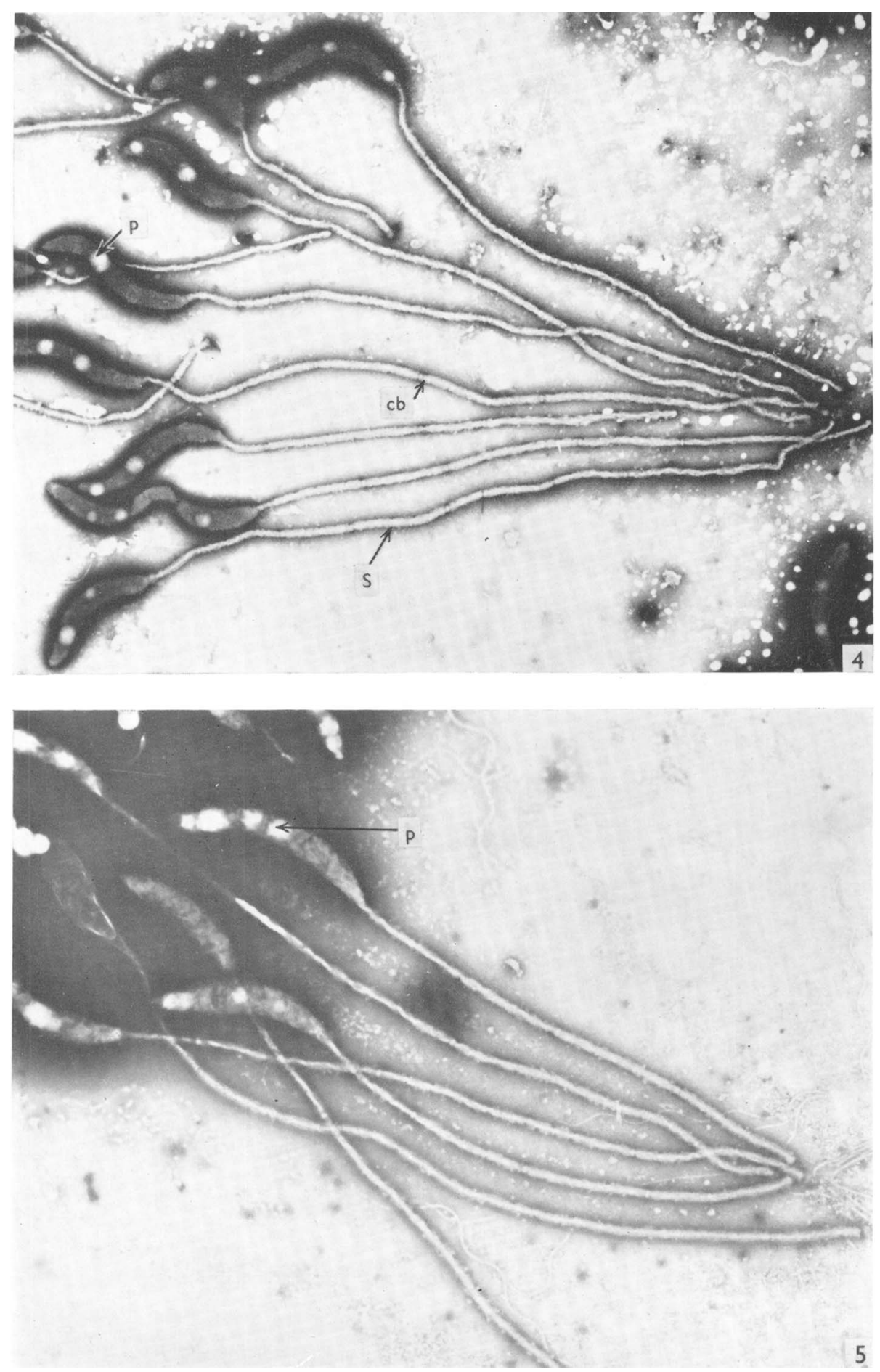

J. M. SCHMIDT 

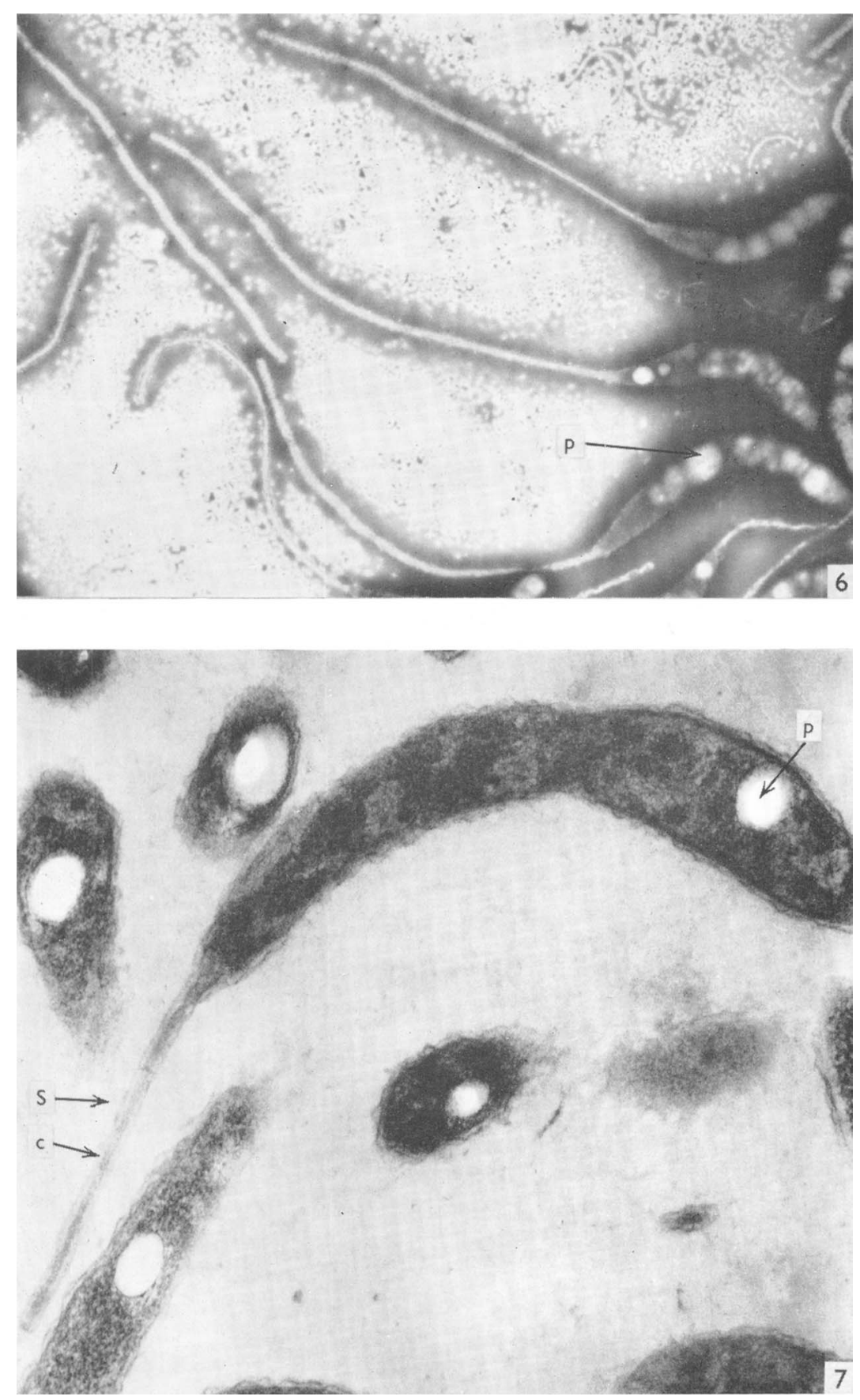

J. M. SCHMIDT 

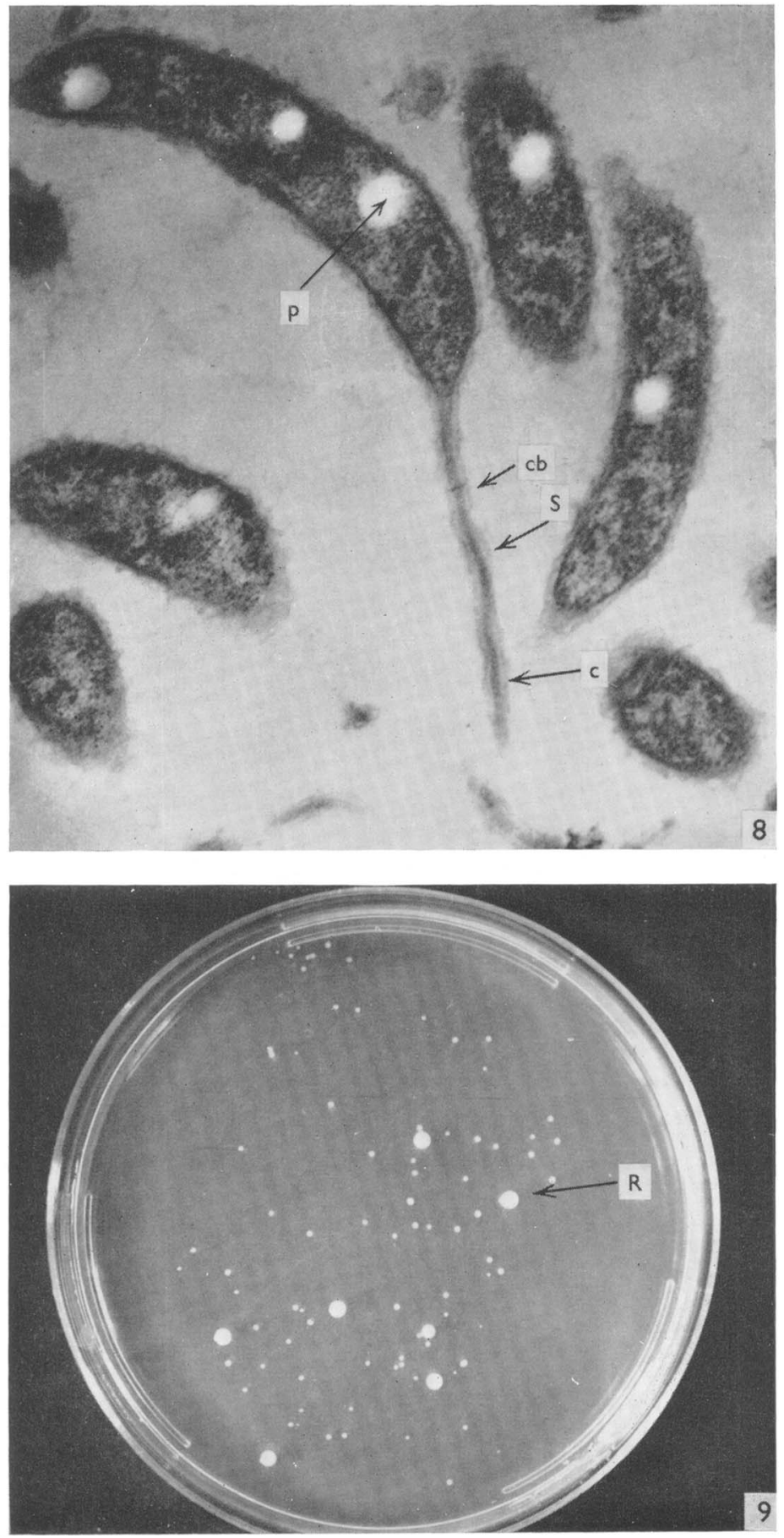

J. M. SCHMIDT 